https://www.scilook.eu/index.php/slif/article/view/slif16-008 DOI: 10.30888/2415-7538.2020-16-02-008

AUTHENTIC AUTHORSHIP PROBLEM AND CONTROL OF STUDENTS' WORK AT THE AGE OF INTERNET GADGETS ПРОБЛЕМА КОНТРОЛЯ АВТОРСТВА СТУДЕНЧЕСКОЙ РАБОТЫ В ЭПОХУ ИНТЕРНЕТА И ГАДЖЕТОВ

Ilchenko E.V. / Ильченко E.В. c.ph.s., as.prof. / к.ф.н., доu. SPIN:8409-2942

NUST MISIS, Moscow, Leninskii Prospect, 4, 119049 НИТУ МИСИС, Москва, Ленинский проспект, 4, 119049

BulanovskayaT.A. / Булановская T.A. SPIN: 4013-4760 c.ph.s., as.prof. / к.ф.н., доu. RGUP, Novocheriomushkinskaya ul,69, 117418 Российский государственный университет правосудия, Новочеремушкинская ул. д.69, 117418

Аннотация. В работе рассматривается проблема аутентичности студенческих работ, не только творческого характера, но и домашних заданий по курсу, контрольных тестов и устных ответов в рамках аудиторной работы. Даются рекомендации по организачии контрольных мероприятий для проверки самостоятельности результатов аудиторной, внеаудиторной работы и проверочных работ. Для этого должны быть задействованы возможности общедоступных компьютерных программ и интернета.

Ключевые слова: контроль, плагиат, списывание, интернет

Вступление.

Проблема плагиата существует в мире дольше, чем понятие авторского права. Заимствование сюжетных ходов и даже целиком повествования одним автором у другого долгое время было в порядке вещей. Постепенно такие действия начали считаться постыдными, и авторы «Буратино» и «Волшебника изумрудного города» подверглись критике, а в последнее время под недреманное око Антиплагиата попал даже Вильям Шекспир, неколько пьес которого американские исследователи Деннис Маккарти и Джун Шлуэтер (Dennis McCarthy, June Schlueter) [1], а до них еще британский ученый Брайен Викерс (Sir Brian Vickers) подвергли проверке с помощью обычной программы, предназначенный для выявления плагиата в работах ленивых и нечестных студентов, которой пользуются университетские профессора.

Проблема плагиата в научных работах, вопросы авторства и приоритета научных открытий также стоит довольно остро в течение последних столетий. Это же касается и студенческих творческих работ, и многие западные авторы уже давно занимаются этой проблемой [2,3 и др].

Сейчас она отчасти решается, пусть несколько грубо и примитивно, с помощью программы «Антиплагиат», не позволяя, по крайней мере, безнаказанно копировать большие куски чужих работ. Эта проблема освещалась одним из авторов настоящей публикации еще в 2009 году в статье «Как распознать плагиат в студенческой работе» [4].

\title{
Основной текст
}

С начала нового столетия волна технического прогресса накрыла и нашу 
страну, и сегодня основная проблема уже в том, что копирование чужих работ происходит с помощью электронных средств ежедневно и ежечасно. Наивные технические хитрости жуликоватого студента в первой новелле «Операции Ы», спрятавшего наушник под повязкой, не идут ни в какое сравнение с виртуозами, получающими информацию прямо под пристальным взглядом экзаменаторов - докторов наук.

Некоторые методисты вообще отказываются от попыток контролировать студентов, предполагая, что лентяй в конечном итоге будет плохим специалистом, которого не возьмут на приличную работу, и он будет таким образом наказан. Например, когда преподавателей НИТУ «МИСИС» знакомили c платформой Touchstone, разработанной в Кембридже [5], которая применяется там сейчас в преподаватии английского языка на инженерных факульетах, на вопрос о том, как гарантировать, что упражнение, которое обучаемый делает на платформе, выполнено именно этим студентом, а не его соседом, англичанин-инструктор несколько высокомерно ответил вопросом вы хотите обучать, или контролировать? Это прозвучало, конечно, гордо, но с практической точки зрения такой подход мало чего дает.

История технического прогресса изобилует примерами того, как изобретенное на благо человечества использовалось в преступных или военных целях. K счастью, возможности компьютера позволяют преподавателю противостоять изобретательности студентов, хотя, конечно, с несколько меньшей эффективностью.

Наиболее простым и доступным является способ, описанный в романе Тома Клэнси «Игры патриотов» [6] как изобретенный ЦРУ для выяснения, кто именно организовал утечку конфиденциальной информации. Для этого с помощью компьютерной программы создавалось некоторое количество именных копий секретного документа, каждая из которых имела незначительные отличия от остальных. Если доступ к документу получали посторонние лица, то по специфической комбинации характеристик можно было выяснить, чья именно копия подверглась утечке.

При проведении контрольной работы довольно легко можно создать не два варианта, а столько, сколько студентов в группе или даже на потоке. Лентяй не сможет воспользоваться чужой работой, потому что его вариант будет отличаться. Так же можно индивидуализировать и домашние работы. Конечно, это потребует дополнительного времени и усилий, но не так много, как в докомпьютерную эпоху.

Для виртуозов, которые умудряются отослать полученное задание и получить ответ от более знающего товарища прямо во время контрольной работы, можно предусмотреть выполнение задания по модулям с жестким ограничением по срокам. То есть работа разбивается на достаточно мелкие части, и на выполнение каждой дается несколько минут. В этом случае осуществить пересылку в две стороны будет затруднительно, если вообще возможно.

Такого же рода ограничение по времени можно предусмотреть для классных работ. Если они выкладываются на платформу, то работа должна 
быть отправлена в течение, например, 10 минут после получения задания. Если задания разные, то времени выполнить и свое, и еще одно для кого-то, просто не будет. Вообще, в зависимости от вида работы, манипуляции с контрольным сроком сдачи предлагают довольно большой диапазон ужесточения контроля.

Некоторые затруднения вызывает также контроль работы реферативного характера, поскольку они предполагают использование чужого материала, хотя и переработанного. Если это обычный реферат, то нет нужды даже прибегать к Антиплагиату. Будучи лентяем, студент обычно не утруждает себя даже поисками менее очевидных источников или компиляцией нескольких, а просто копирует первый попавшийся реферат на аналогичную тему. Достаточно взять из него какую-то более-менее оригинальную, неклишированную фразу и запустить поиск. Вы мгновенно получите результат, а то и несколько, потому что разные авторы часто помещают в интернете скопированные чужие работы, и даже части учебника, выдавая их за свои.

Если работа должна представлять собой конспект, то следует требовать, чтобы он имел вид плана-конспекта, а не связного текста. В этом случае студенту придется прочитать текст, выделить главное и сформулировть его в виде тезиса, что, собственно, и является целью создания конспекта. Если предмет предполагает, что теоретические положения должны сопровождаться примерами, в требованиях к работе предусмотрите обязательное использование оригинальных примеров, и резко снижайте оценку за использование примеров, скажем, из лекции или базового учебника, которые вы легко узнаете.

В том случае, если вы получили две (или больше) одинаковые работы, почти никогда нет никакой возможности определить, кто у кого списал. Поэтому представляется разумным включить в требования к работе условие, при котором одинаковые работы оценки не получают. На требование студента «докажите, что я списал», следует спокойно разъяснить, что вы - не полицейский и не судья, и доказательство вины не входит в ваши служебные обязанности, а о том, что одинаковые работы не будут засчитываться, вы их предупредили. Особо рьяным можно предложить распечатки обеих работ и попросить указать свою. Это быстро мотивирует студентов, которые честно выполняют свои работы, не давать копировать их своим ленивым товарищам. Такой подход можно сравнить с нормой уголовного права, когда наказывается и взяточник, и взяткодатель.

Поймать списывающего при устном опросе гораздо легче, и, скорее всего, ничего нового для себя в этом разделе вы не увидите.

Во-первых, студент, пользующийся шпаргалкой, заметен всегда. Его выдает напряженная поза, которую любой мало-мальски опытный преподаватель видит даже краем глаза. Если вам не хочется проводить унизительную процедуру отъема шпаргалки, можете это проигнорировать, потому что при ответе достаточно задать любой дополнительный вопрос, и студент, не понимающий проблемы, а только скопировавший или даже зазубривший готовый текст, продемонстрирует свою некомпетентность. Можно просто попросить изменить порядок ответа, и, при отсутствии понимания проблемы, экзаменуемый сразу же собьется. 
Если предметом проверки является не знание, а понимание, можно разрешить студентам пользоваться самостоятельно подготовленными вспомогательными материалами, скажем, списком примеров. Это снимает часть стресса у студентов прилежных, заставляет поработать ленивых и нерадивых, а последнее, собственно говоря, и есть одна из целей нашей деятельности.

Бездумное копирование чужой домашней работы затрудняется использованием автоматизированных домашних заданий (АДЗ). Например, на платформе Канвас, которая используется в НИТУ «МИСИС» на лингвистическом факультете, преподаватель на базе программы для тестов может создать тренировочную работу, которую студент может выполнить заданное количество раз, исправляя ошибки в каждой последующей попытке, а за последнюю получить оценку. Порядок ответов на вопросы меняется автоматически, вопросы предъявляются по одному, и узнать, какой ответ неправильный, студент может только после завершения попытки. Скопировать и даже сфотографировать такую работу крайне затруднительно, поэтому каждый должен делать ее самостоятельно. Студенты могут советоваться друг с другом, но они это делают и при выполнении обычной домашней работы. Выполняемый по такому же образцу тест отличается от АДЗ тем, что дается одна попытка, и его выполнение ограничено по времени. Конечно, требовать ответа-рассуждения в таком режиме невозможно, но выполнение этих работ позволяет добиться усвоения базовой информации в рамках предмета. Можно включить в задание ссылки на соответствующие материалы, что позволит студенту быстро просмотреть необходимый раздел перед повторным выполнением задания.

Формат автоматизированной проверки можно также использовать как элемент устного экзамена, хотя, конечно, полностью переводить экзамен в компьютерную форму нецелесообразно, поскольку у студентов и так есть проблемы с оформлением устного высказывания на академическую тему владение терминологией, грамотное оформление своей мысли и т.п., то есть те навыки, которые необходимы ему как специалисту в соответствующей области. Но, при наличии технического обеспечения, можно какую-то часть контроля, например, знание терминологии, проверять на экзамене автоматизированно, в режиме реального времени.

Что касается творческих работ, здесь, помимо Антиплагиата, который обеспечивает лишь техническую проверку совпадений текста, в НИТУ «МИСИС» используется также процедура предзащит. В течение года проводится несколько встреч, где студенты выпускного курса представляют соответствующую степень готовности своей работы комиссии, которая задает вопросы по содержанию работы, направлению исследования, используемым материалам и так далее. Конечно, основная задача таких встреч - не контроль плагиата, а помощь дипломнику и его руководителю, с тем, чтобы работа не содержала серьезных ошибок и имела научную ценность, что всегда обеспечивается коллективным обсуждением. Но они включают в себя и элемент контроля, поскольку выявляют самостоятельность работы автора уже на ранних этапах, а также заставляют его работать равномерно, а не купить, 
например, готовую работу в конце обучения.

Заключение и выводы. Подводя итоги, можно сказать, что проблема использования чужого материала, будь то работы известных специалистов или товарищей по учебе, по-прежнему стоит очень остро. Она усугубляется тем, что в студенческой среде нет понимания таких действий как постыдных, подобных воровству. Можно сделать предположение, что это связано с такой чертой национального характера, которая рассматривает обман власть предержащих как действие оправданное и даже доблестное. В России такое отношение к властям выработалось спецификой многовекового исторического развития и вряд ли в ближайшее время подвергнется изменению. Как убедить студентов, что преподаватели - это не «власть», и обманывают они в случае использования чужого материала самих себя - это проблема, которая пока ожидает своего решения.

В условиях использования студентами электронных средств связи и копирования информации, достаточно эффективными средствами контроля аутентичности авторства работы являются манипулирование контрольными сроками сдачи материала студентами, индивидуализация заданий, поэтапный контроль выполнения относительно больших по объему заданий, использование программы Антиплагиат и сравнительный анализ письменных работ, сданных в электронной форме, в программе Word.

Тем временем, учебный процесс продолжается, и методы контроля должны совершенствоваться параллельно с другими педагогическими и методическими приемами.

Литература:

1. https://www.nytimes.com/2018/02/07/books/plagiarism-software-unveils-anew-source-for-11-of-shakespeares-plays.html

2. Pragmatic Plagiarism: Authorship, Profit, and Power: Marilyn Randall. University of Toronto Press 2001.

3. Plagiarism: Alchemy and Remedy in Higher Education: Bill Marsh.State University of New York Press

4. Ильченко Е.В. Как распознать плагиат в студенческой работе. Третья международная научно-практическая конференция «Общество-язык-культура: актуальные проблемы взаимодействия в XXI веке». Том 1 Москва: МИЛ

5. https://www.cambridge.org/us/cambridgeenglish/catalog/adultcourses/touchstone/online-platform

6. Patriot Games, Tom Clancy (first published August 4th 1987).

Abstract. Today Russian students have access to Internet through a wide range of gadgets, and those, unfortunately, are often used by cheating students to benefit from other people's intellectual efforts, be it academics or just more diligent fellow students. This can be stopped by employing comparatively simple techniques, including sophisticated adjusting of deadlines, creating unique copies of assignments, stage control of longer assignments, and some more. These ensure the authenticity of a student's work authorship and present an objective picture of their progress.

Key words: student's work authorship, plagiarism, control techniques, Internet, gadgets

Статья отправлена: 21.01.2020 г.

(c) Ильченко Е.В., Булановская Т.А. 